\section{Perfect Spheres}

Manufacturing perfectly round geometrical shapes from solid materials requires specialized techniques and careful craftsmanship. Humans first "mass-produced" crude spheres as projectiles to be thrown in siege machinery; later these spheres became smaller and better shaped as ammunition in weapons and, in the industrial age, as bearings in machinery. Recently, on flights of the space shuttles Columbia and Challenger, microgravity experiments with the Monodisperse Latex Reactor produced millions of identical perfect spheres only 10 micrometers across.

Though darts and arrows had been used as projectiles for centuries, they proved to be ballistically. unsound when launched from a firearm. The next alternative was round shot, spherical ammunition that remained the most popular type of projectile until the 19th century, when rifled gun barrels came into use.

The first spherical projectiles fired with gunpowder were made of stone, which was readily available everywhere and had previously been used in the catapult and the ballista as far back as Roman days. The first references to stone ammunition spheres can be found in France in 1346, in Italy 18 years later, and in England 12 years after that. Making the stone spheres was painfully slow; craftsmen chipped away with hammer and chisel for hours on a rough block until it became somewhat round. Even after the advent of metal shot, though, stone continued to be used because it remained cheaper than expensive iron and bronze, and also because stone shot was lighter than equivalent metal spheres, thereby requiring smaller charges of gunpowder. (This not only proved less expensive and safer, but also increased the lifetime of the fragile cannons of the period.)

However, large stone shot tended to break when it struck a stone wall, and so new materials were needed to penetrate defensive walls. Petrarch describes how the Italians began using bronze shot in 1344. At the same time, soldiers in France were using spherical lead projectiles. Iron shot came into general use for hand and shoulder weapons during the reign of Charles VIII of France (1483-1498), though it was mentioned as early as 1350 . All these spheres were cast in molds and worked into a reasonably round shape. Over the course of about a century, iron, lead, and bronze spheres were used interchangeably.

Hollow spheres of cast iron were filled with gunpowder and fired from cannons as explosive "shells" of metal. The Netherlands and Venice seem to have independently developed this idea in the late 14th century. Many other countries rapidly adopted the concept for land battles, though the risks of exploding metal shells were considered too great to be used on a

\section{READY-TO-USE HV AND UHV PUMPING SYSTEM} Highly Mobile TMP Pumping System

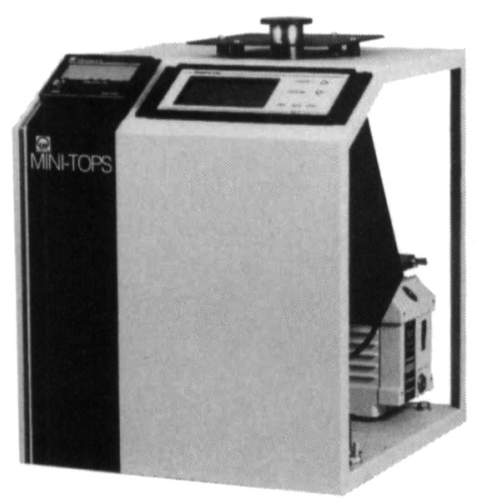
Complete and Ready to Plug-in and Operate

- Hydrocarbon-Free High Ultimate Vacuum - $10^{9}$ mbar with CF Flange

- High Effective Pumping Speed

- Small Footprint, Simple Operation

- Integral Vacuum Vacuum Gauge Controller

For more information, dial 1-800-433-4021 LEYBOLD VACUUM PRODUCTS, INC. 5700 Mellon Road, Export, PA 15632-8900

Innovative Vacuum Technology ship for naval battles. Despite a successful engagement by the French captain Deschiens in 1690-in which his single ship drove off four British vessels and, later, two Dutch through the use of exploding shells-no other naval commander used cast-iron shells until 1788, when Sir Samuel Bentham (formerly of England, and then working in the service of the tsar of Russia) used hollow iron shells to gain a great victory singlehandedly against an entire Turkish fleet. Still, neither the Russians or the British put Bentham's (re)discovery to practice, until General Henri Paixhans of France implemented exploding shells as part of the French navy's weaponry.

While large round shot was used to great effectiveness in cannons to batter walls and buildings, a single cannon ball could do little against massed troops. Occasionally, small lead balls and other shrapnel were packaged in canisters and then fired, which scattered the shot over a wide area. In another system, called grape shot, iron balls were arranged three layers separated by metal plates, producing composite projectile with wide dispersion.

Small hand and shoulder firearms used individual projectiles, which came to be known as bullets, from the French word "boulette," which means "small ball." Early bullets, usually made from soft lead, ranged from 0.6 to 0.8 inches in diameter (1.5 to $2 \mathrm{~cm}$ )

Although early lead bullets varied somewhat in shape, they were usually round. One method for making small lead ammunition was swaging, or cold-shaping, extruded wire in suitable dies, but small shot was most commonly made on a "shot tower." Small lead spheres could be formed in large quantities by pouring the molten metal through a sieve at the top of a wooden or brick tower. The oldest shot towers rose 50 to $100 \mathrm{ft}$ high $(15$ to $30 \mathrm{~m})$, though current ones reach $190 \mathrm{f}$. (58 m).

Since the lowest energy configuration for the molten lead droplets minimizes the surface area per volume, the surface tension draws each shot into a ball as it falls. The lead droplets formed perfect spheres by the time they reached the bottom, where they plunged into a pool of water. The fallen shot was collected from the water, dried, and sorted by size and sphericity. The primary size of lead shot manufactured this way could be varied by increasing or decreasing the gap size in the sieve at the top of the tower.

Lead for shot is usually an alloy containing 2 to $6 \%$ antimony and $1 \%$ arsenic. The additions increase the lead's tensile strength (by up to four times) and also lower its melting point. 
A technique similar to the shot tower is used in modern manufacturing to make microscopic spheres. A monodisperse aerosol generator, consisting of a vibrating membrane and a screen, creates a mist where all particulates are approximately the same size. On Earth, the largest uniform size of spherical particles that can be manufactured by an aerosol reaches only about three micrometers in diameter.

However, in the microgravity environment of the U.S. space shuttle orbiting the Earth, the Monodisperse Latex Reactor (MLR), can produce identical, perfectly spherical particles up to about 10 micrometers in diameter. In a chamber in the shuttle bay, the MLR sprays a solution of liquid latex through four aerosol generators, which create millions of tiny spheres.

The MLR was tested and flown on four of the first nine Shuttle flights: STS-3 and STS-4 on the Columbia in March and June 1982, and STS-6 and STS-7 on the Challenger in April and June 1983. Results showed that such small particles could be made at larger sizes, perhaps up to $20 \mathrm{mi}$ crometers in diameter, and still maintain a consistent size. Once hardened, these latex spheres can be used in many applications back on Earth.

The tiny beads can be applied in industry for calibrating instruments used to measure within tolerances. In medical applications, the latex spheres can be used to carry medication or radioactive isotopes through the bloodstream to tumor sites; they can also be used to determine the sizes of lesions in the eye or the intestine.

Demand for the space-manufactured latex spheres grew so great among souvenir seekers that NASA took to sealing small samples of them inside glass slides, leaving the bulk of them for the uses to which they had been conceived.

Spheres are also used for hardness testing. The Brinell hardness test presses a hardened steel ball, $10 \mathrm{~mm}$ in diameter, into the surface of a test piece, measuring the depth of penetration of the ball under a load of up to $3,000 \mathrm{~kg}$. The test was developed in the late 1800 s by Johan August Brinell of Sweden, and his hardness measuring apparatus was first displayed in 1900 at the Paris Exposition. The test is still one of the most widely used measurements of hardness.

Small glass spheres the size of a pea (5 $\mathrm{mm}$ in diameter) are doped with deuterium and tritium and used in tests for inertial confinement fusion power. Each fusion target contains about $5 \mathrm{mg}$ of deuterium and tritium; lasers will strike the spherical target from all sides, compressing it to a thousand times its original density (about 20 times that of lead), which leads to fusion reactions.

KEVIN J. ANDERSON

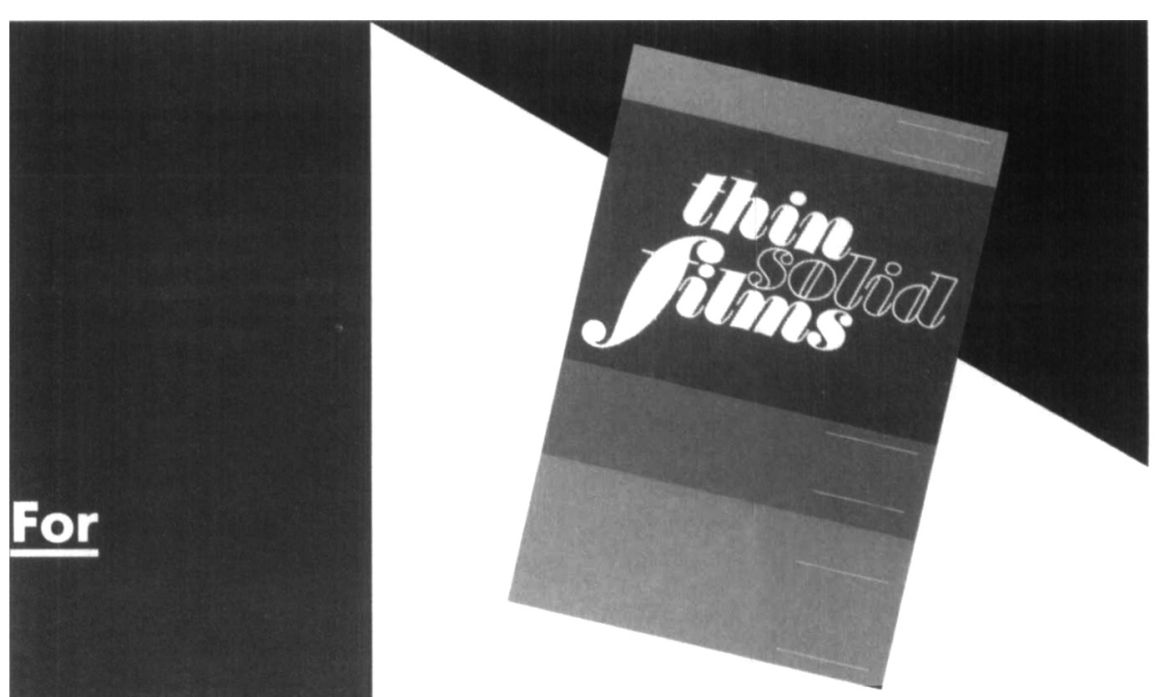

Scientists
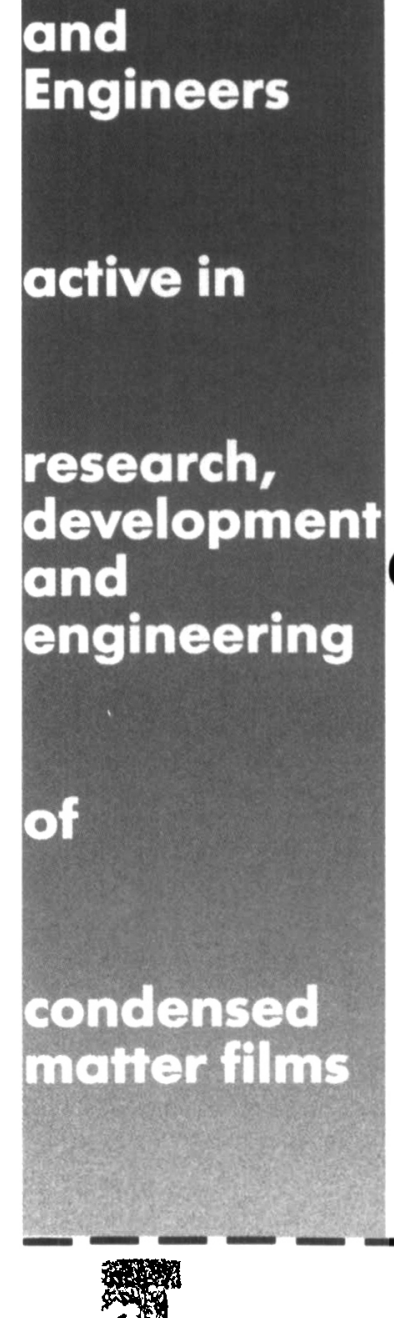

ELSEVIER

SEQUOIA S.A.

P.O. Box 564

$\mathrm{CH}-1001$ Lausanne 1

Switzerland

Tel.: 021/207381

For customers in the U.S.A. and Canada

\section{Elsevier Science}

Publishing Co., Inc.

Journal Information Center 655 Avenue of the Americas New York, NY 10010 , U.S.A. Tel.: (212) 633-3750

\section{The Journal in an evolving Field}

\author{
Editor-in-Chief: J. E. Greene \\ University of Illinois, \\ Urbana, IL, U.S.A.
}

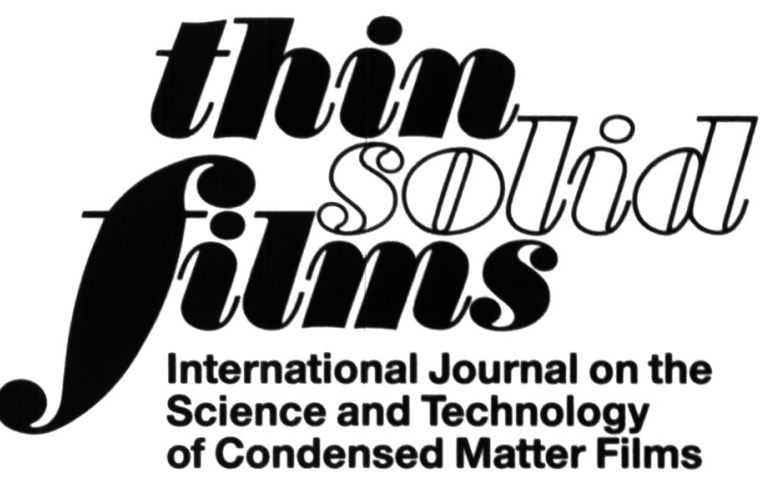

\section{Aims and Scope}

The journal Thin Solid Films is in a unique position to both reflect developments in the evolving field of thin films and to provide guidance and coherence.

The study of thin films is, by nature, highly interdisciplinary, requiring knowledge in areas of physics, chemistry, engineering, and, in some cases, biology. Interests of those in the field span the full spectrum from fundamental studies of adatom/surface interactions and interfacial reactions to device and userrelated applications. Examples of the latter include such diverse specialties as optoelectronics, superconductivity, information storage media, hard wear-resistant coatings, fuel cells, and bio-compatible coatings.

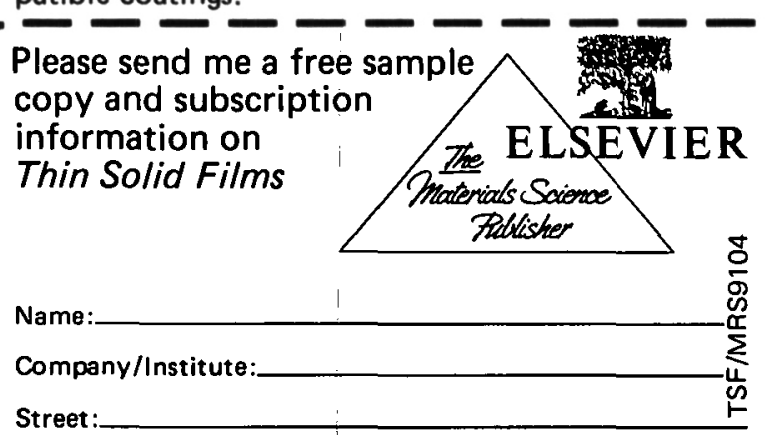

City:

Postal Code: Country:

Date: Signature

Please visit Booth No. 334 at the MAS Show in Anaheim, CA, April 30-May 2, 1991. 